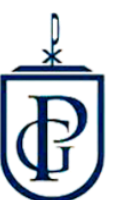

Veritas Et Scientia

Vol. $7, N^{\circ} 1,788-799$

Enero - Junio del 2018.

ISSN $2307-5139$

\title{
EL MATRIMONIO CIVIL DE LOS/AS HOMOSEXUALES Y LA VULNERACIÓN DEL RESPETO PLENO DE LOS DERECHOS HUMANOS EN EL PERÚ, AÑO 2016
}

THE CIVIL MARRIAGE OF HOMOSEXUALS AND THE VULNERATION OF THE FULL RESPECT OF HUMAN RIGHTS IN PERU, YEAR 2016

Francisco García Rivera ${ }^{1}$

Presentado: 25/11/2017

Aceptado: 04/01/2018

Publicado online: 11/06/2018

\section{RESUMEN}

Por la presente investigación se pretende analizar las posturas justicias de los operadores de justicia de la provincia de Tacna respecto si se vulneran los derechos humanos fundamentales de las personas con orientación homosexual al no permitírsele contraer matrimonio civil en el Perú, en el año 2016. Se llevó a cabo un estudio de tipo básica y de carácter cualitativo. Asimismo, se aplicaron los siguientes métodos de investigación: analítico, deductivo, comparativo, hermenéutico, sintético. La muestra final estuvo compuesta por 334 abogados. Asimismo, se revisaron diversos documentos de utilidad para la investigación: Constitución Política del Perú, Jurisprudencia de la Corte Interamericana de Derechos Humanos, Convención Americana sobre Derechos Humanos, Código Civil del Perú, Tribunal Constitucional del Perú, Leyes de países o Estados donde se aprobaron leyes facultando el matrimonio civil entre personas del mismo sexo, Declaración Universal de Derechos Humanos, Carta Internacional de Derechos Humanos, Conferencia Mundial de Derechos Humanos y Asamblea del Milenio, Prevención de la Discriminación de los Derechos Humanos en la Administración de Justicia. Se encontró que aproximadamente la mitad de los juristas asumen posturas jurídicas a favor del matrimonio igualitario u homosexual en el Perú. Sin embargo, es mayoritario el sector de juristas que no aprueban la legalización del matrimonio homosexual.

Palabras clave: Homosexualidad, matrimonio, derechos humanos, discriminación, derecho a la igualdad.

\footnotetext{
${ }^{1}$ Doctor en Derecho
} 


\begin{abstract}
The purpose of this research is to analyze the justiciary positions of justice operators in the province of Tacna regarding the violation of the fundamental human rights of persons with homosexual orientation by not being allowed to contract civil marriage in Peru in 2016. In order to meet the proposed objectives, a basic type and qualitative study was carried out. Also, the following research methods were applied: Analytical method, deductive method, comparative method, hermeneutic method, synthetic method. The investigation was carried out in the province of Tacna. The final sample consisted of 334 lawyers. In addition, various documents useful for the investigation were reviewed: Political Constitution of Peru, Jurisprudence of the Inter-American Court of Human Rights, American Convention on Human Rights, Civil Code of Peru, Peruvian Constitutional Court, Laws of countries or States where they were approved Laws granting civil marriage between persons of the same sex, Universal Declaration of Human Rights, International Charter of Human Rights, World Conference of Human Rights and the Millennium Assembly, Prevention of discrimination against human rights in the administration of justice. It was found that approximately half of the jurists surveyed assume legal positions in favor of equal or homosexual marriage in Peru. However, the majority of lawyers surveyed do not approve the legalization of gay marriage.
\end{abstract}

Keywords: Homosexuality, marriage, human rights, discrimination, right to equality.

\title{
INTRODUCCIÓN
}

El matrimonio es considerado como la forma más común de apareamiento entre personas de sexo distinto, desde hace siglos. La antigüedad de los enlaces de varones y mujeres no puede ponerse en duda, pues desde la Patagonia hasta Alaska, desde Noruega hasta Sudáfrica, todos los grupos humanos, indistintamente de sus condiciones, nivel de desarrollo o idiosincrasia admiten la unión de varones y mujeres con fines de apareamiento, procreación de hijos y formación de unidades familiares.

Desde tiempos inmemoriales, la familia nuclear fue la unión familiar más común entre las otras formas de familia. Ciertamente, existen otras formas de familias: familias extendidas, familias monoparentales familias homosexuales, etc. Pero es la familia nuclear la predominante en todas las culturas y grupos humanos alrededor del mundo. Sin embargo, en los últimos años, la familia nuclear ha venido sufriendo lo que podría llamarse ataques denodados, desde sectores liberales que la cuestionan y proponen otras formas de familia para la sociedad moderna. Estas nuevas formas de familia incluyen, por supuesto, las familias homosexuales: es decir, familias formadas por varón y varón y por mujer y mujer.

En el Perú ya existen iniciativas ciudadanas e incluso de carácter legislativo que buscan la aprobación de leyes que les permitan a personas del mismo sexo casarse con todas las prerrogativas y derechos que tales uniones permite el sistema jurídico peruano.

El Código Civil vigente desde 1984, en su Art. 234 define el matrimonio como la unión voluntariamente concertada entre un hombre y una mujer, a fin de hacer vida común" (Leg. Peruana., 1984). Asimismo, la Constitución Política del Perú a través del Art. 5 alude a la unión estable de un varón y una mujer. Sin embargo, a raíz de los cambios acaecidos en el último medio siglo, otros tipos de unión han surgido, como aquellas parejas del mismo sexo, que luego buscan unirse en matrimonio. El 
homosexualismo es una práctica que se ha dado en todos los tiempos de la historia.

El hecho de ser diferente implica a una minoría de personas y trae consigo muchas consecuencias como es el ser estigmatizado/a, prejuiciado/a, marginado/a y/o discriminado/a. Y siempre la sexualidad es y ha sido un tema sensible, ya que para esta minoría implica no estar inmerso dentro de los patrones que la sociedad impone. Existe así un "paradigma dominante", en este caso la heterosexualidad, que es lo que corresponde a la mayoría del grupo social, y que mediante diversas ideas suele denominar a esas personas como "personas enfermas o perversas" a las personas que son capaces de atreverse a distinguir su opción sexual ante la mayoría (Buquet, 2004). Con respecto a lo que corresponde a la sexualidad de las personas ya en los campos de la psicología, psiquiatría, religión y el derecho mismo (legalidad) tiende a definir lo correcto y normal, de lo desviado y anormal, como ocurre específicamente en el caso de los hombres y mujeres homosexuales. La Declaración Universal de Derechos Humanos y los instrumentos internacionales de ella derivados (Organización de las Naciones Unidas-ONU, 1955) se adoptaron para que en el mundo dejara de haber ciudadanos excluidos.

El artículo 10 de la Declaración de los Derechos del Hombre y del Ciudadano (Francia, 1789) se estableció que: "Todos los hombres nacen y viven libres e iguales en derechos; las distinciones sociales solo pueden fundarse en la utilidad común. Plantear que la prohibición del matrimonio entre personas del mismo sexo por el sistema jurídico -constitucional peruano vulnera los derechos humanos de las personas homosexuales, no quiere decir que se acepta sin discusión el matrimonio homosexual; pero si se sostiene, como sociedad, que la libertad y el bienestar de las personas son valores fundamentales. La unión entre personas del mismo sexo en algunas jurisdicciones se le denomina pacto civil de solidaridad o sociedad de convivencia (Sáez Capel, 2011). Montiel (2012), señala que el matrimonio entre personas del mismo sexo es un tema del derecho universal, que considera que casarse y formar una familia es un derecho que asiste a todas las personas. Etcheverry (2015) postula que la regulación de las uniones homosexuales se ha vuelto un debate cotidiano en la actualidad. Smith et al (SmithCastro \& Molina-Delgado, 2011) refieren que una combinación particular de alta ortodoxia religiosa, alto autoritarismo homofóbico y poco contacto con personas homosexuales disminuyen las probabilidades de apoyar el matrimonio y la unión civil en Costa Rica. Bustillos (Bustillos, 2011), muestra un análisis comparativo, de carácter empírico, sobre la situación actual de los matrimonios entre personas del mismo sexo probando su existencia como preocupación en países de América y Europa. Rubín (Rubin, 2011) afirma que no existen las razones suficientes que justifiquen privar de la protección que brindan el sistema jurídico o el aparato estatal, a los matrimonios entre personas del mismo sexo. Vásquez y Barcía (2008), contribuye con argumentos jurídicos que permitan construir una futura regulación para las parejas del mismo sexo que pretendan contraer matrimonio. Domínguez (Dominguez \& Yessenia, 2015), refiere que existe discriminación cuando se señala que el Matrimonio procede únicamente entre un hombre y una mujer, y que el Matrimonio igualitario se concreta en el logro del reconocimiento de vínculos actuales otorgando el mismo status y valor que las relaciones heterosexuales. Carrillo (Carrillo Flores, 2016) considera las diversas tendencias que han llevado a un inminente cambio en la percepción del matrimonio. McLean, Schnitzler, Camean y Villar (2010) refieren que el derecho debe seguir la realidad biológica y antropológica del matrimonio y promover y defender sus bienes humanos y sociales protegiendo las instituciones básicas de la vida social. En una unión homosexual no se dan los presupuestos biológicos y antropológicos de la complementariedad conyugal. Bosch (2015) afirman que el conocimiento de personas homosexuales en el entorno directo tiene un efecto positivo en la actitud hacia ciertos aspectos de la homosexualidad, comparado con el grupo que conoce homosexuales, pero no en el entorno directo. Ortiz (Ortiz, 2014) identifica el matrimonio civil con otra clase matrimonial de indudable trascendencia socio-jurídica en la historia española: el matrimonio canónico. Suárez(Suarez, 2017) señaló que los argumentos religiosos y biologistas parten de depositar todo lo negativo sobre las personas homosexuales haciéndolas responsables de los males sociales y por ende se eximen del análisis personal y grupal. 
Bajo una perspectiva del derecho comparado, el reconocimiento de las uniones homosexuales se ha dado a través de dos vías distintas: vía judicial (a través de sentencias de tribunales judiciales) y vía legislativa (Rodríguez, 2010). Álvarez-Gayou (2013), afirma que: "Junto a la institución del matrimonio, y en muchos casos como alternativa, existen instituciones civiles adicionales, muy diferentes en cada país y comunidad, con denominaciones distintas, como "parejas de hecho" o "uniones civiles", cada cual de una naturaleza, requisitos y efectos ad hoc, según la realidad social, histórica, sociológica, jurídica y política de cada sociedad". Viera- Álvarez (2008) refiere que la unión civil es uno de los varios términos usados para un estado civil similar al matrimonio, creados típicamente para permitir el acceso de las parejas homosexuales a la mayor parte de las ventajas gozadas por las parejas heterosexuales casadas, sin llegar a otorgarles totalmente la igualdad en derechos con el matrimonio.

El rectorado de la Universidad Austral (Buenos Aires-Argentina refiere que: "El matrimonio, que es una estructura de unión personal con propiedades de exclusividad y permanencia, que da solidez y garantía jurídica a la convivencia de personas y a los hijos que surjan de dicha unión, encuentra su razón de ser en la diversidad radical y originaria del varón y de la mujer y en su unión complementaria biológica y antropológica, fuente de comunión y de vida, que funda el núcleo familiar" (Universidad Austral, 2010). Por su parte, Macedo (1997) señala que: "El valor de la familia, y lo que justifica su protección, está en que forma un núcleo de personas que se unen y comparten la vida en razón de existir sentimientos fuertes como el afecto". Fernando Cavanillas de Blas desarrolla los fundamentos católicos contrarios el matrimonio homosexual: "A la unión legal de un hombre con una mujer (sexos diferentes) se le llama Matrimonio. Por lo tanto, la unión de dos hombres (con sexos iguales y que no pueden procrear entre sí) nunca puede ser Matrimonio por rotunda imposibilidad física y biológica, ya que ninguno de los dos contrayentes posee matriz" (Cavanillas de Blas, 2016, citado en es.catholic.net). Respecto a la libertad de acción es conveniente tener en cuenta lo que señala Hervada (1998), quien explica que la libertad fundamental tiene dos aspectos: la libertad de decidirse a hacer o no hacer (libertad de ejercicio) y la libertad de elegir hacer una cosa u otra (libertad de especificación). En esa línea se expresa Medina (2001) al señalar que la ideología individualista tan frecuente en nuestra sociedad pretende fundar los derechos humanos naturales sin referencia a ningún orden o ley objetiva natural.

Al respecto, cabe tener en cuenta que dentro del esquema teórico de Nino la moral posee dos dimensiones: la primera se refiere a la moral privada o auto referente, esto es, la que tiene por contenido el conjunto de ideales de excelencia personal que evalúan las acciones de los individuos por sus efectos en la calidad de vida del propio agente. La segunda dimensión, la moral social o intersubjetiva, se refiere al conjunto de principios que valoran o enjuician las acciones de los individuos por sus efectos sobre los intereses de otros sujetos distintos del agente. Según estas premisas la autonomía moral significa la libre aceptación de principios morales intersubjetivos y de ideales autorreferentes de excelencia personal (Parmigiani, 2011). Martínez (1996) manifiesta que el derecho es esencialmente intersubjetivo. La autonomía, en opinión de Martínez es una autointerpretación de la propia acción que no permite emanciparse del error o del autoengaño, lleva a exteriorizar las consecuencias de los actos(Seclén, 2014).

\section{OBJETIVOS}

a. Determinar la postura jurídica de los operadores de justicia, analizar la doctrina internacional y fundamentos jurídicos sobre el derecho al matrimonio civil de los/as homosexuales en la provincia de Tacna.

b. Proponer la modificación del Art. 5 de la Constitución Política del Perú y el Art. 234 del Código Civil y demás normas concordantes y afines, para que dos personas del mismo sexo puedan contraer matrimonio en defensa del derecho a su identidad. 


\section{METODOLOGÍA}

Investigación no experimental de tipo básica y de carácter cualitativa. Analítica deductiva. Utiliza el método hermenéutico a través de la recolección de datos empíricos. La investigación se llevó a cabo en la provincia de Tacna. Comprendió un periodo de tiempo de 13 meses: diciembre del 2015 y desde enero a diciembre de 2016. Las unidades de estudio son los Abogados que litigan en la Provincia de Tacna con una muestra total de 334 profesionales. Se utilizó las técnicas de la encuesta asistida.

\section{RESULTADOS}

Según una encuesta llevada a cabo el año 2014 por IPSOS Perú para el diario El Comercio, el 61\% de la población peruana rechaza la unión civil entre parejas homosexuales, mientras que un $33 \%$ sí está a favor de que las parejas puedan compartir su patrimonio (AMERICA TV, abril 2014). El siguiente año, las cifras porcentuales de rechazo al matrimonio igualitario u homosexual se incrementó. Un $79 \%$ de la población peruana estaba en desacuerdo con el matrimonio homosexual y un $89 \%$ señala que la familia es el aspecto más valorado en nuestra sociedad, según revela la reciente encuesta nacional urbana a cargo de la consultora VOX POPULI (Fuente: RPP, julio 2015). Según la última encuesta de GFK el $68 \%$ de peruanos rechaza el matrimonio igualitario (presentado como "unión civil" por el congresista Carlos Bruce), mientras que sólo un 15\% las apoya (fuente: PERU 21, agosto 2016). En este año 2017, la encuestadora $\mathrm{CPI}$, señaló que el $82.2 \%$ de peruanos rechaza la iniciativa llevada al congreso recientemente por las congresistas del Frente Amplio, Marissa Glave e Indira Huilca (PERÚ 21, febrero 2017).

La discriminación es, según Shelton (2003): “Cualquier distinción negativa por la cual se priva a alguien de la igualdad de oportunidades o trato en su trabajo y su ocupación, que se base en cuestiones de raza, color, sexo, religión, opiniones políticas, origen nacional o social". La tabla 01 presenta que el $38.3 \%$ de la muestra considera que la prohibición del matrimonio entre personas del mismo sexo afecta el derecho a la no discriminación, el $41.6 \%$ opina lo contrario y un $17.1 \%$ están de indecisos.

Tabla 1: ¿Considera que la prohibición del matrimonio entre personas del mismo sexo afecta el derecho a la no discriminación?

\begin{tabular}{lll}
\hline Opciones & $\mathrm{f}$ & $\%$ \\
\hline $\mathrm{Si}$ & 128 & 38.3 \\
$\mathrm{No}$ & 139 & 41.6 \\
$\mathrm{Ns} / \mathrm{Nr}$ & 57 & 17.1 \\
\hline $\begin{array}{l}\text { Total } \\
\text { Fuente: Encuesta asistida }\end{array}$ & 334 & $100 \%$
\end{tabular}

El 62.6\% considera que para evitar abusos contra homosexuales o su desamparo legal, no hace falta aprobar legalmente el matrimonio homosexual. Para la mayoría de abogados, los abusos contra esta comunidad no disminuirían con la aprobación de leyes respecto del matrimonio igualitario. Sin embargo, un $18.6 \%$ opina que la aprobación del matrimonio igualitario u homosexual disminuiría los abusos en contra de esta comunidad (Tabla 02). 
Tabla 02: Disminución de abusos contra homosexuales disminuiría con aprobación legal del matrimonio homosexual

\begin{tabular}{lll}
\hline Opciones & $\mathrm{f}$ & $\%$ \\
\hline $\mathrm{Si}$ & 62 & 18.6 \\
$\mathrm{No}$ & 209 & 62.6 \\
$\mathrm{Ns} / \mathrm{Nr}$ & 63 & 18.8 \\
\hline $\begin{array}{l}\text { Total } \\
\text { Fuente: Encuesta asistida }\end{array}$ & 334 & $100 \%$
\end{tabular}

Con respecto a la afirmación: "Cómo puede decirse que el principal fin del matrimonio es la procreación, si no todas las parejas casadas tienen hijos, no todos los hijos nacen dentro del matrimonio y, con las nuevas tecnologías y la ayuda de una tercera persona de sexo opuesto, las parejas del mismo sexo pueden tener hijos", el $43.4 \%$ de la muestra coincide con la lógica que encierra esta afirmación. Sin embargo, el $31.4 \%$ de la muestra no está de acuerdo con la lógica.

Casi la mitad de la muestra cree que los fines del matrimonio no han evolucionado a través del tiempo y que estos siguen siendo los mismos que los de hace mucho tiempo atrás.

Respecto a si los matrimonios de parejas infértiles son inválidos jurídicamente, El 81.7\% de la considera que no está de acuerdo con que los matrimonios de parejas infértiles sean declarados inválidos jurídicamente. Es obvio que este alto porcentaje de letrados de la ciudad de Tacna asuman que el matrimonio no solo tiene como objetivo la procreación sino otros propósitos. Se halló que el 53.6\% de la muestra Sí está de acuerdo con la afirmación: "Los matrimonios de parejas del mismo sexo afecta a la institución del matrimonio como tal". Los críticos del matrimonio igualitario creen que lo que se reconoce legal y socialmente no es sólo el consentimiento personal sino también un consentimiento social que contribuye al futuro de la sociedad al tener y criar hijos. Aunque no todas las parejas casadas tengan hijos, la relación entre un hombre y una mujer tiene el potencial inherente de crear hijos. Los críticos del matrimonio homosexual creen que permitir a las parejas del mismo sexo casarse cambiaría la definición de matrimonio hasta tal punto que dejaría de ser matrimonio.

Respecto a la afirmación: "Si se les permitiera casarse a las parejas del mismo sexo, entonces sus uniones se consolidarían y sus hijos se verían mejor protegidos, puesto que el reconocimiento les quitaría el estigma social", un $61.4 \%$ de la muestra NO está de acuerdo. Este importante porcentaje de abogados encuestados creen que la aprobación del matrimonio igualitario no guarda relación con la disminución del estigma social asociado a la homosexualidad. Tampoco cree que las uniones entre personas del mismo sexo consolidarían su relación si se aprobara el matrimonio homosexual. Contrariamente, el $29.3 \%$ de la muestra sí piensa que la aprobación del matrimonio igualitario ayudaría a disminuir el estigma social asociado a la homosexualidad.

El $49.4 \%$ cree que es jurídicamente constitucional permitir a las parejas homosexuales contraer matrimonio. Por el contrario, el $44.1 \%$ opina lo contrario. Sólo 22 abogados encuestados (6.5\%) no supo afirmar o negar estar de acuerdo con la afirmación. El 56.6\% cree que la aprobación legal del matrimonio homosexual produciría un grave deterioro en la estructura moral del país. La opinión 
mayoritaria de abogados de la ciudad de Tacna sorprende por la visión "catastrófica" que tienen acerca de la posible aprobación del matrimonio igualitario en el Perú.

La Real Academia Española de la lengua define el concepto de igualdad como: "Conformidad de algo con otra cosa en naturaleza, forma, calidad o cantidad.". Respecto a la igualdad ante la ley, la Real Academia señala que corresponde al "Principio que reconoce a todos los ciudadanos capacidad para los mismos derechos". Por su parte, el Tribunal Constitucional chileno, afirma que "La igualdad ante la ley consiste en que las normas jurídicas deben ser iguales para todas las personas que se encuentren en las mismas circunstancias y, consecuencialmente, diversas para aquellas que se encuentren en situaciones diferentes. (...) Así, se ha concluido que la razonabilidad es el cartabón o standard de acuerdo con el cual debe apreciarse la medida de igualdad o la desigualdad". En ese sentido, el $49.7 \%$ de los letrados de la ciudad de Tacna opinan que la prohibición del matrimonio homosexual en el Perú vulnera el derecho a la igualdad, reconocido constitucionalmente; mientras que el $37.7 \%$ opinan que la prohibición del matrimonio igualitario no vulneran derechos constitucionales.

El 58.1\% de la muestra está de acuerdo que la prohibición del matrimonio igualitario u homosexual implica una afectación al derecho a la identidad de la persona que se reconoce como de orientación homosexual.

Al analizar la doctrina internacional, en España consideran que:

El matrimonio en la constitución española es una garantía institucional y, simultáneamente un derecho constitucional.

El tribunal español considera que hay que examinar si la regulación impugnada impide el ejercicio del derecho por parte de las personas heterosexuales, en las mismas condiciones en que anteriormente lo ejercían, afectando por tanto el contenido esencial de ese derecho. El tribunal resolvió que no afecta el contenido esencial del derecho, porque el que puedan contraer matrimonio entre sí personas del mismo sexo no lo desnaturaliza, ni lo convierte en otro derecho, ni impide a las parejas heterosexuales casarse libremente o no casarse.

En Argentina, el tribunal analiza si la prohibición de contraer matrimonio para la pareja recurrente constituye una discriminación del Estado basada en la orientación sexual. En un primer examen literal, los artículos cuestionados se contraponen directamente con las reglas constitucionales que prohíben un trato discriminatorio en razón de la orientación sexual. Los actores se hallan impedidos de acceder a la categoría socialmente aprobada de "casados".

En Uruguay el tribunal considera que el ordenamiento jurídico uruguayo evolucionó desde la entrada en vigor de la ley de identidad de género, la cual habilita el matrimonio entre personas del mismo sexo, aunque no lo diga expresamente. Por lo que el tribunal considera que desde ese momento no es aplicable la excepción de orden público internacional, en base a que dicho principio se encuentra fuertemente debilitado.

En Estados Unidos en el 2015, la Corte señala que: Sería no entender a estos hombres y mujeres decir que faltan el respeto a la idea del matrimonio. Su justificación es que ellos lo respetan, lo respetan tan profundamente que tratan de cumplirlo por sí mismo. No deben estar condenados a vivir en soledad, excluidos de una de las instituciones más antiguas de la civilización. Piden la misma dignidad ante los ojos de la ley. La Constitución les otorga ese derecho.

En México, la reforma de modificación del Código Civil donde se permite el matrimonio homosexual, ha redefinido - según el máximo Tribunal - el concepto de matrimonio, como la unión entre dos personas, extendiendo, de esta manera, esa institución civil a las personas homosexuales. Dice el Tribunal que la modificatoria no afecta o trastoca dicha institución en cuanto a su núcleo esencial o su naturaleza, como aduce el accionante, ni tampoco podría sostenerse que la Constitución se opone a esa opción elegida por el legislador ordinario, como tampoco que sea sólo el matrimonio 
entre un hombre y una mujer, el medio para constituir una familia ideal.

En Italia la Corte señaló que le corresponde al parlamento, referirse y legislar acerca del matrimonio homosexual.

En Alemania, El Tribunal Constitucional, luego de la dictación de la ley que permitió las uniones civiles homosexuales, señala que dicha normativa no vulnera la Constitución, ya que no se establecen las uniones civiles en desmedro del matrimonio y no se ve afectada la institución matrimonial en ningún aspecto. Agrega que la protección al matrimonio no implica que no puedan existir otros tipos de regulaciones de pareja.

Fundamentos Jurídicos a favor del matrimonio civil homosexual en el Perú

"Artículo 1. La defensa de la persona humana y el respeto de su dignidad son el fin supremo de la sociedad y del Estado". (Constitución Política del Perú).

El artículo $4^{\circ}$ de la Constitución Política del Perú establece lo siguiente: “Artículo 4.- Protección a la familia. Promoción del matrimonio. (...) También protegen a la familia y promueven el matrimonio. Reconocen a estos últimos como institutos naturales y fundamentales de la sociedad.

El artículo V del Título Preliminar del Código Procesal Constitucional establece: "El contenido y los alcances de los derechos constitucionales protegidos por los procesos regulados en el presente Código deben interpretarse de conformidad con la Declaración Universal de Derechos Humanos, los tratados sobre derechos humanos, así como de las decisiones adoptadas por los Tribunales Internacionales sobre derechos humanos constituidos según tratados de los que el Perú es parte".

Que, el primer párrafo del artículo $2^{\circ}$ de la Declaración Universal de Derechos Humanos, establece lo siguiente: "Artículo $2^{\circ}$. - Toda persona tiene los derechos y libertades proclamados en esta Declaración, sin distinción alguna de raza, color sexo, idioma, religión, opinión, política o de cualquier otra índole, origen nacional o social, posición económica, nacimiento o cualquier otra condición".

El Estado Peruano ha suscrito el Pacto Internacional de Derechos Civiles y Políticos. Este Pacto Internacional de Derechos Civiles y Políticos señala que las leyes contra la homosexualidad son una violación de los derechos humanos.

La Convención Interamericana sobre Derechos Humanos, en su artículo $24^{\circ}$ establece lo siguiente: "Todas las personas son iguales ante la ley. En consecuencia, tienen derecho sin discriminación a la igual protección de la ley".

Fundamentos jurídicos de quienes apoyan la inconstitucionalidad del matrimonio civil de los/las homosexuales en el Perú

1ㅇ Fundamento:

Código Civil. "Artículo 234.- Noción del matrimonio: El matrimonio es la unión voluntariamente concertada por un varón y una mujer legalmente aptos para ella y formalizada con sujeción a las disposiciones de este Código, a fin de hacer vida común. El marido y la mujer tienen en el hogar autoridad, consideraciones, derechos, deberes y responsabilidades iguales".

20 Fundamento:

Constitución Política del Perú. “Artículo 5.- La unión estable de un varón y una mujer, libres de impedimento matrimonial, que forman un hogar de hecho, da lugar a una comunidad de bienes sujeta al régimen de la sociedad de gananciales en cuanto sea aplicable". 


\section{DISCUSIÓN}

El análisis de los textos, resoluciones, sentencias denegatorias al matrimonio homosexual, opiniones de juristas, organismos no gubernamentales, personalidades del ámbito político nacionales y extranjeros, juristas de la ciudad de Tacna, entre otros, permite concluir que los fundamentos jurídicos de quienes apoyan la inconstitucionalidad del matrimonio civil de los/as homosexuales en el Perú están basado casi exclusivamente en la concepción de la familia en su rol fundamental de procreación de hijos.

La vulneración de los derechos fundamentales de las personas de orientación homosexual se constata con dos argumentos principales: En la carta Magna en la Cuarta Disposición Final y Transitoria establece lo siguiente: "Las normas relativas a los derechos y a las libertades que la Constitución reconoce se interpretan de conformidad con la Declaración Universal de Derechos Humanos y con los tratados y acuerdos internacionales sobre las mismas materias ratificados por el Perú", y b) el artículo $V$ del Título Preliminar del Código Procesal Constitucional establece: "El contenido y los alcances de los derechos constitucionales protegidos por los procesos regulados en el presente Código deben interpretarse de conformidad con la Declaración Universal de Derechos Humanos, los tratados sobre derechos humanos, así como de las decisiones adoptadas por los Tribunales Internacionales sobre derechos humanos constituidos según tratados de los que el Perú es parte". Por lo tanto, el Estado Peruano no cumple con el Pacto Internacional de Derechos Civiles y Políticos. Este Pacto Internacional de Derechos Civiles y Políticos señala que las leyes contra los derechos fundamentales de las personas homosexuales son una violación de los derechos humanos.

Tampoco el Estado Peruano cumple con la Convención Interamericana sobre Derechos Humanos, en su artículo $\mathrm{N}^{\circ} 24^{\circ}$ establece lo siguiente: "Todas las personas son iguales ante la ley. En consecuencia, tienen derecho sin discriminación a la igual protección de la ley." El análisis de la Constitución Política del Perú y de los tratados internacionales suscritos por el Estado Peruano, permite determinar que si existe vulneración del respeto pleno de los derechos humanos fundamentales de las personas con orientación homosexual al no permitírsele contraer matrimonio civil en el Perú. Se logró comprobar que NO es mayoritaria la percepción de los operadores de justicia de la provincia de Tacna, en el año 2016, respecto de si la prohibición del matrimonio homosexual vulnera los derechos humanos fundamentales de las personas con orientación homosexual. Por lo tanto, una mayoría de juristas de la ciudad de Tacna, obviando normas constitucionales y fundamentos jurídicos nacionales e internacionales, asumen posiciones en contra del matrimonio homosexual en el Perú.

Se encontró, que aproximadamente la mitad de los juristas encuestados asumen posturas jurídicas a favor del matrimonio igualitario u homosexual en el Perú. Sin embargo, es mayoritario el sector de juristas encuestados que no aprueban la legalización del matrimonio homosexual en el Perú.

Hace falta desarrollar una nueva percepción de la Carta Fundamental de la República Peruana para que, en primer lugar, los operadores del derecho desarrollen una percepción evolutiva de los principios y normas contenidas en la Constitución Política del Perú. Es decir, frente a la visión "estática" o "inamovible" de la Carta Magna, se opone una visión "evolutiva", "cambiante". Tal como lo plantea la doctrina canadiense que entiende que el "Corpus Jurídico" de un país debe ser considerado como un "árbol vivo". Es decir, los letrados de la ciudad de Tacna deben interpretar evolutivamente las leyes de la república, "acomodando" o adaptando las leyes a las realidades actuales. Los letrados de la ciudad de Tacna deberían recordar que si bien es cierto que el Código Civil de la República establece en su artículo 234 que "El matrimonio es la unión voluntariamente concertada por un varón y una mujer legalmente aptos para ella y formalizada con sujeción a las disposiciones de este Código, a fin de hacer vida común". Sin embargo, también es cierto que dicha disposición legal no pueden ser contrarias a la propia Constitución, que en su artículo 2, Inciso 2, dice: Toda persona tiene derecho a: A la igualdad ante la ley. Nadie debe ser discriminado por motivo de origen, raza, sexo, idioma, religión, opinión, condición económica o de cualquiera otra índole (Constitución Política del Perú). Entonces, según la 
conocida Pirámide de Kelsen, la Carta Magna es la norma de mayor jerarquía, por lo que en caso de conflicto con otros dispositivos legales, tendrá que prevalecer la primera.

Cualquier proyecto de ley con el objetivo de legalizar el matrimonio igualitario o de personas del mismo sexo que se presente al Congreso de la República Peruana para su aprobación, debe incluir el concepto de evolución y cambio en la realidad social, cultural, económica, demográfica de la sociedad peruana. Esta constatación de cambios en la realidad nacional en todos sus aspectos y sectores, debe hacer posible la adaptación de las leyes nacionales a esta realidad cambiante y en constante evolución. Lo contrario no es lógico y resulta escasamente racional: Esto es: adaptar la realidad social, cultural o económica al Corpus Legal que regula la vida de la nación.

\section{REFERENCIAS BIBLIOGRÁFICAS}

Bustillos, J. (2011). Derechos humanos y protección constitucional. Breve estudio sobre el matrimonio entre personas del mismo sexo en México y en perspectiva comparada, 30.

Carrillo Flores, I. (2016). Democracia y educación en la formación docente. Vic: Servei de Publicacions de la UVic-UCC : Eumogràfic.

Dominguez, D., \& Yessenia, A. (2015). El matrimonio homoafectivo y el principio de igualdad en el caso peruano. Universidad Autonoma del Peru. Recuperado a partir de http://localhost/xmlui/handle/AUTONOMA/181

Leg. Peruana. (1984). Código Civil. Decreto Legislativo No 295. Libro II. Derecho de Familia. Noción del matrimonio Artículo 234. Recuperado a partir de http://www.oas.org/juridico/PDFs/mesicic4_per_cod_civil.pdf

Ortiz, J. F. (2014). La eficacia civil del matrimonio canónico y de las decisiones eclesiásticas en el derecho español* Civil Effects Of Canonical Marriage And Ecclesiastical Judgments Under Spanish Law, 34.

Parmigiani, M. (2011). Intersubjetividad y autorreferencialidad en la teoría ética de C.S. Nino. Diánoia, 56(66), 105-139. Recuperado a partir de http://www.scielo.org.mx/scielo.php?script=sci_abstract\&pid=S0185$24502011000100005 \& \operatorname{lng}=e s \& n r m=i s o \&$ tIng=es

Rubin, G. (2011). "El sueño que me parece más atractivo es el de una sociedad andrógina y sin género (aunque no sin sexo), en que la anatomía sexual no tenga ninguna importancia para lo que uno es, lo que hace y con quién hace el amor»., 92.

Seclén, I. E. C. (2014). ¿Podemos redefinir el matrimonio? La protección jurídica del matrimonio frente a las uniones entre personas del mismo sexo en el Perú, 32.

Smith-Castro, V., \& Molina-Delgado, M. (2011). Actitudes hacia el matrimonio y la unión civil gay en Costa Rica: ¿religiosidad, homofobia, autoritarismo o desconocimiento? Interamerican Journal of Psychology, 45(2), 133-143. Recuperado a partir de http://www.redalyc.org/articulo.oa?id=28422741004

Suarez. (2017). Proyecto de Ley de Unión Civil entre personas del mismo sexo. Posiciones a favor y en contra. Recuperado a partir de file:///C:/Users/VICTOR/Downloads/DialnetProyectoDeLeyDeUnionCivilEntrePersonasDelMismoSexo-3921916.pdf

Álvarez-Gayou (2013). Los rostros de la homosexualidad: Una mirada desde el escenario. México DF: Ed. Manual Moderno

Bosch, M. (2015). Actitudes hacia la homosexualidad. Una comparación entre personas de 18 a 30 años en España y los Países Bajos. (Investigación). Lugar: Universidad de Utrecht-Holanda

Buquet, A. (2004). Sexualidades diversas. Aproximaciones para su análisis. Programa Universitario de 
Estudios de Género. Secretaria Técnica. Universidad Nacional Autónoma de México.

Código Civil. Decreto Legislativo № 295. Libro II. Derecho de Familia. Noción del matrimonio Artículo 234. Recuperado de: http://www.oas.org/juridico/PDFs/mesicic4_per_cod_civil.pdf Constitución Política del Perú. Capítulo II. De los derechos sociales y económicos. Recuperado de: $\quad$ http://spij.minjus.gob.pe/CLP/contenidos.dll?f=templates\&fn=defaultconstitucion.htm\&vid=Ciclope:CLPdemo

Constitución de la República Argentina. Recuperado de: https://www.educ.ar/dinamico/UnidadHtml get_2e9f5840-c853-11e0-82e0e7f760fda940/anexo3.htm

Constitución Política de la República de Bolivia. Derechos humanos. Recuperado de: http://www.cejamericas.org/index.php/biblioteca/biblioteca-virtual/doc_view/2732-losderechos-humanos-en-las-constituciones-derechosciviles-y-pol\%C3\%ADticos-nodiscriminaci\%C3\%B3n-e-igualdad-ante-la- ley.html

Constitución Política de la República de Colombia. Recuperado de: http://www.constitucioncolombia.com/titulo-2/capitulo-1/articulo-13

Constitución Política de los Estados Unidos Mexicanos. Recuperado de: http://www.diputados.gob.mx/LeyesBiblio/htm/1.htm

Coronado (2007). Escalas de medición. Paradigmas, Vol 2, (2). Bogotá, D. C. (julio- diciembre de 2007), pp. 104 -125. ISSN 1909-4302 @ Corporación Universitaria Unitec.

Etcheverry, J. (2015). Constitucionalidad del matrimonio homosexual. Tesis para optar al grado de Licenciado en Ciencias Jurídicas y Sociales. Universidad de Chile. Facultad de Derecho. Departamento de Derecho Público.

Fernández-Noa, Y. (2008). Yucatan Today, La guía turística. Recuperado el 18 de noviembre de 2011, de: El Matrimonio Maya. Recuperado de: http://yucatantoday.com/es/topics/el-matrimoniomaya

Hervada, J. (1998). Cuatro Lecciones de Derecho Natural. Ediciones. Pamplona: Universidad de Navarra S.A

Martínez de Aguirre, C. (1996). Diagnóstico sobre el derecho de familia. Análisis sobre el sentido y los contrasentidos de las transformaciones contemporáneas del Derecho de familia. Madrid: Ediciones RIALP

McLean, L., Cianciardo, J., Schnitzler, E., Camean, C. y Villar, M. (2010). Matrimonio homosexual y adopción por parejas del mismo sexo: informe de estudios científicos y jurídicos y experiencia en otros países (Informe). Argentina

Medina, G. (2001). Los homosexuales y el derecho a contraer matrimonio. Buenos Aires: Rubinzal Culzoni Editores

Montiel, J. (2012). La violación de los derechos humanos de las personas homosexuales para contraer matrimonio en el estado de Yucatán. Tesis para optar el título de abogado por la Universidad de Yucatán. México.

Maritain, J. (2003). Los derechos del hombre y la ley natural. Buenos Aires: Editorial Descleé De Brouwer.

Organización de las Naciones Unidas-ONU (1955). Declaración universal de derechos humanos. ONU. Recuperado de: http://www.un.org/es/documents/udhr/

Rodríguez, E. (2010). El reconocimiento de las uniones homosexuales. Una perspectiva de derecho comparado en américa latina. Boletín Mexicano de Derecho Comparado, nueva serie, año XLIV, núm. 130, enero-abril de 2011, pp. 207-235

Santamaría, M. (2015). Propuesta de ley reformatoria a los artículos 119 de la ley de personal de fuerzas armadas y 18 del reglamento general a la ley de personal de fuerzas armadas. Universidad Regional Autónoma de los Andes. Facultad de jurisprudencia. Carrera Derecho. Tesis de grado 
previo a la obtención del título de abogada de los tribunales, de la República del Ecuador.

Sáez-Capel, J. (2011). Matrimonio del mismo sexo: Estado de la cuestión en distintos países. En: M. T. Ayllón Trujillo, \& M. R. Nuño, Familia, Identidad y Territorio. Factores y agentes en la construcción de ciudadanía democrática (págs. 261-281). México: eumed.net.

Shelton, D. (2003). Prohibición de discriminación en el derecho internacional de los derechos humanos. $\begin{array}{llll}\text { Anuario de Humanos. } & \text { Recuperado } \\ \text { http://www.anuariocdh.uchile.cl/index.php/ADH/article/viewFile/13488/13756 }\end{array}$

Viera- Álvarez, C. (2008). El concepto de familia y la unión civil de personas del mismo sexo. Comentario de jurisprudencia a la aplicación de la ley de violencia intrafamiliar. Revista Nomos - Universidad de Viña del Mar - № 1 (2008), pp. 199 